\title{
Haemodynamic changes due to systemic arterial shunts in a destroyed lung mimicking pulmonary thromboembolism on CT
}

\author{
Samir Mustaffa Paruthikunnan, ${ }^{1}$ Ramakrishna Narayanan, ${ }^{1}$ Anand Abhishek, ${ }^{1}$ \\ Kadavigere Rajagopal ${ }^{2}$
}

${ }^{1}$ Department of Radiodiagnosis and Imaging, Kasturba Medical College, Manipal University, Manipal, Karnataka, India ${ }^{2}$ Department of Radiology, Kasturba Medical College, Manipal University, Manipal, Karnataka, India

\section{Correspondence to} Dr Samir Mustaffa

Paruthikunnan,

samir.pm.19@gmail.com

Accepted 8 August 2015
CrossMark

\begin{tabular}{l}
\hline To cite: Paruthikunnan SM, \\
Narayanan R, Abhishek A, \\
et al. BMJ Case Rep \\
Published online: [please \\
include Day Month Year] \\
doi:10.1136/bcr-2015- \\
211746 \\
\hline
\end{tabular}

\section{DESCRIPTION}

A 51-year-old woman presented to our department with multiple episodes of massive haemoptysis. She had a history of pulmonary tuberculosis. High-resolution CT scan showed a completely destroyed right lung with fibrocavitatory changes (figure 1). CT pulmonary and bronchial angiography was performed, which showed non-enhancement of the right pulmonary artery in the pulmonary angiographic phase, leading to suspicion of a pulmonary arterial embolus (figure 2). The bronchial angiographic phase showed brilliant enhancement of the right pulmonary artery and its branches through reversed filling via multiple systemic collaterals arising from the hypertrophied right bronchial, right intercostal and right inferior phrenic arteries (figure 3).

In patients with chronic pulmonary parenchymal inflammation, such as bronchiectasis, pulmonary

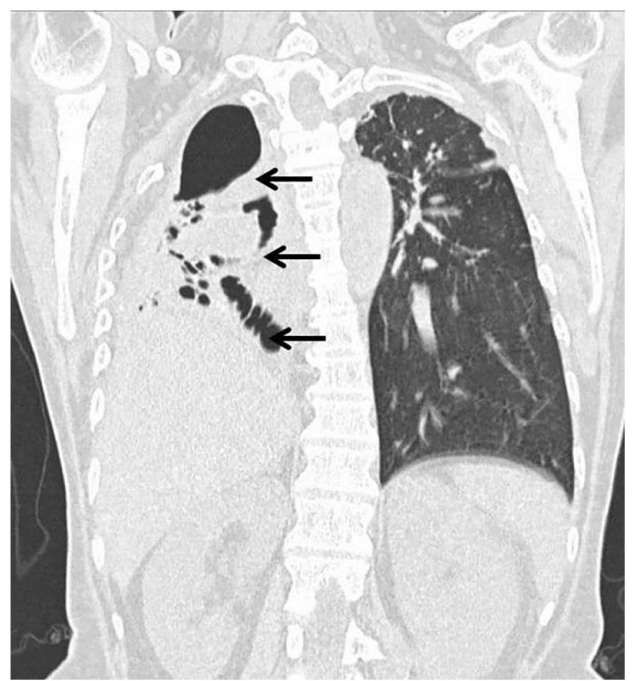

Figure 1 Coronal high-resolution CT (HRCT) image showing complete destruction of right lung parenchyma with fibrocavitatory and bronchiectatic changes (black arrows).

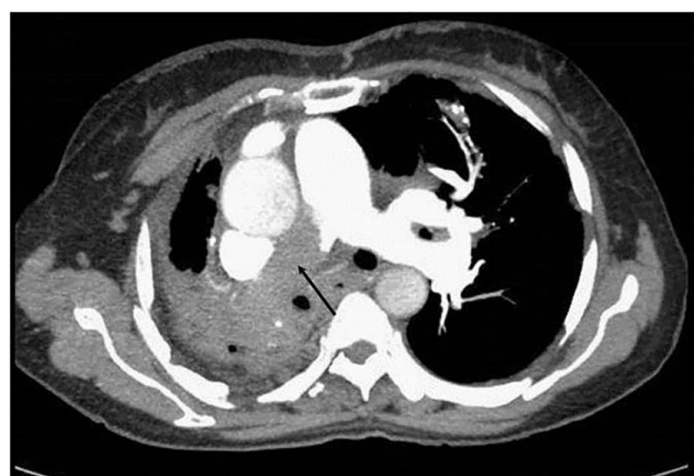

Figure 2 Axial CT image in pulmonary angiographic phase showing non-opacification of the right pulmonary artery (black arrow), simulating pulmonary thromboembolism.

tuberculosis and chronic obstructive pulmonary disease, pre-existing connections between the bronchial and pulmonary arteries become functional at precapillary and postcapillary levels, often creating a source of haemoptysis. ${ }^{1}$

Cases with systemic-pulmonary artery shunts have demonstrated a sharp reduction of pulmonary arterial flow on the affected side with retrograde filling of the pulmonary artery from the systemic circulation. This can be explained by the pressure gradient between systemic and pulmonary circulations that leads to physiological cut-off of the pulmonary arterial flow on the affected side. ${ }^{2}$

This phenomenon was responsible for nonopacification of the affected pulmonary artery in the pulmonary angiogram phase simulating thromboembolism in our case; however, the brilliant opacification in systemic arterial phase demonstrated patency of the pulmonary artery.

Our case demonstrates the importance of including a systemic arterial phase in cases having severe lung destruction, to prevent the misdiagnosis of pulmonary thromboembolism. 


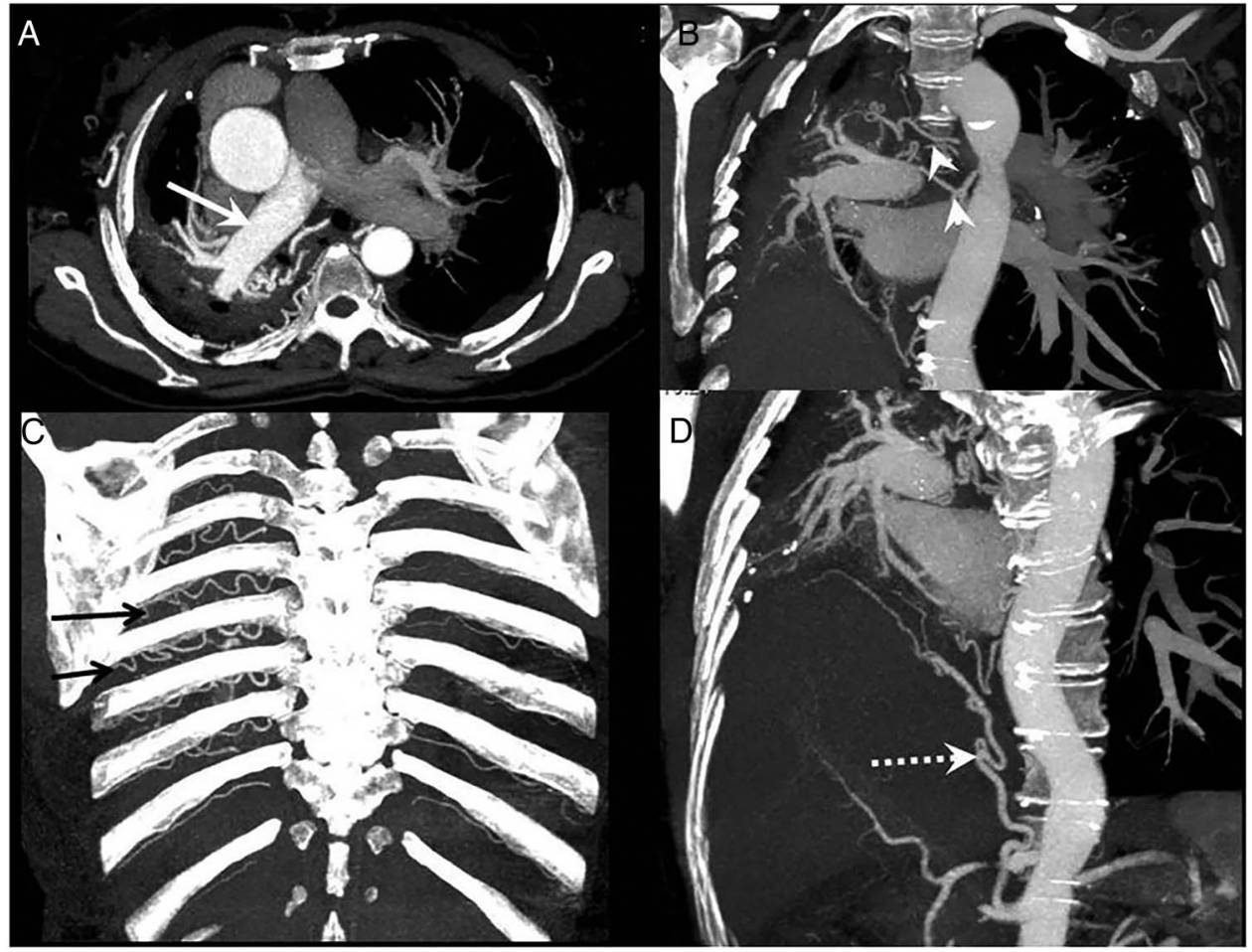

Figure 3 (A) Axial CT image in bronchial (systemic) angiographic phase showing hyperenhancement of right pulmonary artery (solid white arrow). (B-D) Maximum intensity projection (MIP) images in coronal plane showing hypertrophied and tortuous right bronchial arteries (white arrowheads in (B)), right posterior intercostal arteries (black arrows in (C)) and right inferior phrenic artery arising from right renal artery (dotted white arrow in (D)) forming shunts with the right pulmonary artery.

\section{Learning points}

- Conditions causing extensive pulmonary inflammation and destruction can lead to development of systemic-pulmonary shunting.

- These systemic-pulmonary shunts can lead to changes in the pressure gradients of the pulmonary circulation and alteration of haemodynamics.

- Adding a systemic angiographic phase in addition to a pulmonary angiographic phase prevents misdiagnosis of pulmonary thromboembolism in such patients.
Competing interests None declared.

Patient consent Obtained.

Provenance and peer review Not commissioned; externally peer reviewed.

\section{REFERENCES}

1 Do KH, Goo JM, Im JG, et al. Systemic arterial supply to the lungs in adults: spiral CT findings. RadioGraphics 2001;21:387-402.

2 Agmy GM, Wafy SM, Mohamed SAA, et al. Bronchial and nonbronchial systemic artery embolization in management of hemoptysis: experience with 348 patients. ISRN Vasc Med 2013;2013: Article ID 263259, 7 pages.

Copyright 2015 BMJ Publishing Group. All rights reserved. For permission to reuse any of this content visit http://group.bmj.com/group/rights-licensing/permissions.

BMJ Case Report Fellows may re-use this article for personal use and teaching without any further permission.

Become a Fellow of BMJ Case Reports today and you can:

- Submit as many cases as you like

- Enjoy fast sympathetic peer review and rapid publication of accepted articles

- Access all the published articles

- Re-use any of the published material for personal use and teaching without further permission

For information on Institutional Fellowships contact consortiasales@bmjgroup.com

Visit casereports.bmj.com for more articles like this and to become a Fellow 